\title{
A ÉTICA PROTESTANTE E O ESPÍRITO EMPREENDEDOR: EVIDÊNCIAS EMPÍRICAS DO BRASIL
}

\section{THE PROTESTANT ETHIC AND ENTREPRENEURSHIP: EMPIRICAL EVIDENCE FROM BRAZIL}

\author{
Luan Vinicius Bernardelli ${ }^{1}$ \\ Lechan Colares Santos ${ }^{2}$ \\ Gustavo Henrique Leite de Castro ${ }^{3}$ \\ Ednaldo Michelon 4
}

\section{RESUMO}

As constantes alterações no cenário econômico brasileiro impactaram diretamente os níveis de desemprego, obrigando os agentes a tomarem decisões importantes em relação a manutenção de suas rendas. Uma das alternativas utilizadas para essa finalidade é o empreendedorismo, via criação do próprio negócio. Contudo, tomar esta decisão envolve diversos fatores, sendo importante identificá-los e mensurá-los. Assim, o presente estudo objetivou analisar as características que determinam a decisão de empreender e estimar como a religião pode afetar essa decisão. Mais especificamente o estudo verificou a relação entre a religião protestante e a decisão de empreender, controlando para outros fatores apontados pela literatura. Para tanto, a base de dados utilizada foi construída por meio dos microdados dos Censos Demográficos de 1991, 2000 e 2010. Os dados foram modelados por meio do modelo de Regressão Logística e os resultados apontam que ser protestante eleva as chances de ser empreendedor em $10,30 \%, 8,2 \%$ e $2 \%$, respectivamente em relação a 1991, 2000 e 2010 e 3,3\% em relação a amostra total, mostrando que a religião é um fator que deve ser considerado ao se analisar os determinantes do empreendedorismo.

Palavras-chave: empreendedorismo; comportamento religioso; protestantismo, comportamento econômico

\footnotetext{
1 Visiting Scholar na Southern Cross University (SCU) e Doutorando em Teoria Econômica pela Universidade Estadual de Maringá. Mestre em Teoria Econômica pela Universidade Estadual de Maringá (2017). E- mail: luanviniciusbernardelli@gmail.com

2 Possui graduação (2007) em Administração e mestrado (2012) em Administração pela Universidaele Federal de Mato Grosso do Sul. Atualmente é Doutorando em Administração pela Universidade Estadual de Maringá (UEM) e professor mestre da Universidade do Oeste Paulista (UNOESTE). Email : lechancolares@hotmail.com

3 Doutorando em Desenvolvimento Econômico pela Universidade Federal do Paraná (UFPR). Mestre em Economia Regional pela Universidade Estadual do Norte do Paraná (UENP), possui graduação técnica em Contabilidade pelo Centro Paula Souza-SP (2010). Professor da pós-graduação (lato sensu) em Economai Emnresarial da Universidade Estadual de Londrina (UEL).

E-mail: castro.guh@gmail.com

4 Doutor em Ciências Econômicas pela Unicamp - Universidade Estadual de Campinas e pela Universidade da Califórnia. É Professor Associado da Universidade Estadual de Maringá (UEM E-mail: emichellon@uem.br
} 


\begin{abstract}
The constant changes in the Brazilian economic scenario had a direct impact on the levels of unemployment, forcing the agents to make important decisions regarding the maintenance of their incomes. One of the alternatives used for this purpose is entrepreneurship, through the creation of the business itself. However, making this decision involves several factors, and it is important to identify and measure them. Thus, the present study aimed to analyze the characteristics that determine the decision to undertake and estimate how the religion can affect this decision. More specifically the study sought to verify the relationship between the Protestant religion and the decision to undertake, controlling for other factors pointed out in the literature. To do so, the database used was constructed through the microdata of the Demographic Censuses of 1991, 2000 and 2010.The data were modeled through the Logistic Regression model and the results show that being Protestant raises the chances of being entrepreneur in $10,30 \%, 8,2 \%$ and $2 \%$, respectively in relation to 1991,2000 and 2010 and 3 , $3 \%$ in relation to the total sample, showing that religion is a factor that must be considered when analyzing the determinants of entrepreneurship.
\end{abstract}

Key-words: entrepreneurship; religious behavior; Protestantism, Economic behavior

Códigos JEL: Z12; L26

\title{
INTRODUÇÃO
}

A dinâmica internacional frente à globalização tem causado sérias mudanças no cenário mundial, de modo que são exigidas novas atitudes dos profissionais e maior agilidade entres as empresas. As grandes companhias estão se fragmentando, efetivando parcerias com pequenas empresas e esse processo fez com que as atividades antes delegadas aos empregados, são repassadas aos pequenos empreendimentos que, muitas vezes, são terceirizados. Não existe a segurança no emprego e as rápidas e constantes mudanças tecnológicas criam defasagem entre os profissionais, que necessitam estar preparados para atender as exigências impostas por este novo mercado de trabalho (COSTA; WOLF, 2006). Nesse cenário, o mercado de trabalho exige um profissional proativo, inovador, assertivo, e que saiba se adaptar às constantes mudanças do seu meio. Surge, então, um termo para definir este profissional o "empreendedor".

Segundo Dornelas (2003), no Brasil, o empreendedorismo começou a ganhar força a partir da década de 1990, com a abertura da economia. Com a entrada de produtos importados, os preços tiveram um melhor controle, condição importante para o país voltar a crescer, porém, trouxe problemas para alguns setores que não conseguiram concorrer com os importados, como o caso dos setores de brinquedos e de confecções. Essa situação obrigou às empresas a se modernizarem para poder competir e voltarem a crescer. Desta forma, o governo deu início a várias reformas, controlando a inflação e ajustando a economia. O capital estrangeiro voltou a ser aplicado no Brasil e as exportações aumentaram. Ainda para o autor, as micros e pequenas empresas estão ganhando mais espaço e importância na economia, sendo responsável por empregarem mais da metade do emprego formal no Brasil.

No entanto, as vagas de empregos oferecidas não são suficientes para absorver a grande demanda. Observa-se, então, o crescimento do desemprego e de subempregos. Dessa forma, para o trabalhador se manter no mercado de trabalho é 
necessária uma constante qualificação. Nesse cenário, muitas pessoas se destacam pelo aproveitamento de oportunidades, pela criatividade e pela facilidade de adaptarse em um ambiente incerto, aproveitando e transformando recursos em renda. Um fator-chave para a percepção de oportunidades e assunção de risco está relacionada àsquestões culturais que moldam o comportamento do indivíduo (GARTNER, 1988).

Ao se relacionar questões culturais, diversos são os elementos envolvidos em sua construção e um dos fatores que exercem influência nessa relação é a religião, fato já pontuado por diversos autores como Laveleye (1985) ${ }^{5}$, Boswell (1986), Mesquita e Ribeiro (2007), Smith (2007)6, Vieira e Jacinto (2013), Weber (2013) ${ }^{7}$.

Muitos estudos tratam do impacto da religião no mercado de trabalho e no rendimento dos indivíduos, tal como Kortt e Dollery (2012), Kortt et al. (2013), Sinnewe et al. (2016) retratando a importância dessa variável no comportamento dos agentes econômicos.

A partir dos aspectos teóricos destacados sobre a importância do empreendedorismo no Brasil, aliado aos autores que retratam e indicam características empreendedoras no comportamento dos protestantes como Martes e Rodrigues (2004) e Mesquita e Ribeiro (2007) e Vieira e Jacinto (2013), realizam-se os seguintes questionamentos: (i) quais são os fatores que contribuem para a decisão de ser ou não empreendedor? e (ii) existe relação com a religião?

Dessa forma, o presente trabalho tem como objetivo analisar os determinantes da decisão de empreender, evidenciando análises sobre o contexto religioso, mais especificamente o estudo buscou verificar a relação entre a religião protestante e a decisão de empreender.

Embora existam alguns estudos que avaliem a afiliação religiosa e a decisão de empreender a partir de métodos qualitativos, como Martes (2004), Mesquita (2007) e Serafim, Martes e Rodriguez (2012) e também a partir de métodos quantitativos, derivados com Microdados do Censo Demográfico de 2010, como Vieira (2013), não foram encontrados na literatura trabalhos que avaliem de forma representativa essa relação de 1991 a 2010. Além disso, embora o trabalho de Vieira (2013) apresente fundamentos importantes à literatura em questão, não faz a distinção necessária entre os protestantes pentecostais e tradicionais.

Essas questões são especialmente importantes ao se analisar o Brasil, uma vez que de acordo com Bernardelli e Michellon (2018a) elevou-se substancialmente a proporção da população protestante no Brasil de 1991 a 2010. Dessa forma, ao se enfatizar o período de maior mudança no campo religioso brasileiro, este trabalho contribui à literatura por fornecer os primeiros resultados sobre o impacto da relação entre a religião protestante e a decisão de empreender no período da mais alteração religiosa do Brasil.

Apresentada a introdução, o trabalho conduz à próxima seção, que contém referencial teórico para breve contextualização do estudo, definições e conceitos a respeito do tema abordado; já na seção seguinte, apresenta-se alguns estudos empíricos que relacionam religião e empreendedorismo; em seguida, são abordados os procedimentos metodológicos utilizados na condução da pesquisa. Posteriormente são apresentados os resultados e discussões. E, finalmente, nas as considerações

\footnotetext{
5 Obra original publicada em 1875.

6 Obra original publicada em 1776.

7 Obra original publicada em 1904.
} 
finais, são acompanhadas das principais limitações e as sugestões para pesquisas futuras.

\section{A RELIGIÃO E O EMPREENDEDORISMO}

O empreendedorismo é um tema de significativo interesse na academia. No que tange ao seu conceito, uma diversidade é apresentada na literatura, mas para os fins deste estudo, o conceito adotado foi o proposto por Gartner (1988) e Thornton (1999). Para os autores o empreendedorismo é a capacidade de criar empreendimentos e está associado a traços e habilidades específicas do indivíduo. $\mathrm{O}$ mesmo conceito é apresentado por Reynolds (2005) e pode ser definido como a descoberta de oportunidades e a subsequente criação de nova atividade econômica, muitas vezes, por meio da criação de uma nova organização.

De forma genérica, a função empreendedora relacionada ao comportamento empresarial é concebida por meio de uma infinidade de fatores que moldam o comportamento do indivíduo (GARTNER, 1988; THORNTON, 1999; REYNOLDS, 2005). Capacidade de inovação, assunção de riscos e visualização de oportunidades passam a ser características do empreendedor (STEVENSON; JARILLO, 2007).

Essas características não surgem por acaso e conforme aponta Eckhardt (2003), fatores ligados ao funcionamento das instituições moldam a cultura e valores sociais dos indivíduos e, portanto, o seu comportamento para atividade empresarial, uma vez que a atividade empresarial é também uma atividade humana e não ocorre espontaneamente apenas devido ao ambiente econômico ou tecnológico. Dessa forma, é possível considerar que o empreendedorismo, ou comportamento empreendedor, está associado a uma ação, sendo essa ação um processo complexo e resultado de muitas influências, inclusive a religião (SERAFIM; MARTES; RODRIGUEZ, 2012).

Há que se destacar outro importante elemento, a ideia de predestinação divina. Embora esse conceito não seja tão aparente, convém destacar que o indivíduo vocacionado acredita ser parte presente de um plano superior maior. Dessa forma, o sucesso do empreendimento está prioritariamente ligado a uma vontade divina e, portanto, mais resistente as eminentes dificuldades (ENOQUE; BORGES; BORGES 2015).

Assim, é pertinente enfatizar que o presente trabalho adota a abordagem da economia da religião ao considerar que o comportamento empreendedor está relacionado à cultura e às práticas sociais. Essa abordagem é adequada, em virtude que, dentre os diversos fatores culturais elencados pelos autores que estudam o fenômeno do empreendedorismo, ênfase especial tem sido prestada ao papel da religião. Estudos de diferentes nacionalidades retratam o forte vínculo entre a afiliação religiosa e o empreendedorismo (ENOQUE; BORGES; BORGES, 2015). E, de fato, não se pode negar que as profundas mudanças na espiritualidade é um fator importante para se entender as atuais alterações nos ambientes de trabalho (TECCHIO; ALMEIDA CUNHA; SANTOS, 2016).

No que tange às ações práticas sociais, Rüpke (2016) aponta que a religião, quando se refere a instâncias pragmáticas pode ir além dos mecanismos usuais para legitimar o empreendedorismo e pode até mesmo oferecer um campo de ação. No entanto, no presente estudo, especificamente, o conceito de empreendedorismo terá como foco a criação de um negócio próprio ou auto emprego. Assim, faz-se necessário enfatizar que para fins desta pesquisa o conceito de empreendedorismo está relacionado com o de empregador. Portanto, extrapola o significado que relaciona o 
empreendedorismo a um tipo de comportamento e adota o empreendedorismo como ocupação. Tal conceito foi similarmente empregado nos estudos de Gartner (1988) e Thornton (1999).

Em referência à cultura brasileira e ao seu aspecto religioso, o país foi oficialmente católico por quase quatro séculos, dado que a conquista e a colonização realizada por Portugal além de aspectos econômicos e culturais, o país impôs sua religião predominante e mesmo depois de ter se tornado uma nação independente em 7 de setembro de 1822, manteve-se oficialmente unida a Igreja católica ao novo Estado-nação (GAARDER; HELLERN; NOTAKER, 2005).

O catolicismo só deixou de ser a religião oficial no Brasil no final do século XIX, quando a monarquia foi substituída pelo regime republicano, o qual abriu mão da religião oficial, mas cujo mando não deixou de existir, se estendendo durante muito tempo. Hoje, a situação do quadro religioso brasileiro é de competição pluralista entre as mais diversas religiões (GAARDER; HELLERN; NOTAKER, 2005). E, é exatamente o pluralismo religioso que causa distintos conceitos culturais e diferem as ações e as reações dos indivíduos, o que caracteriza um intrínseco conceito institucional.

De forma geral, o cristianismo é a filosofia de vida que mais fortemente caracteriza a sociedade ocidental. Há 2 mil anos permeia a história, a literatura, a economia e a filosofia. Assim, conhecer o cristianismo é pré-requisito para compreender a sociedade e a cultura ocidental (GAARDER; HELLERN; NOTAKER, 2005).Por conseguinte, com base nas fundamentações de Barro e Mccleary (2003),Neri e Melo (2011), Mariano (2013), Weber (2013) entre outros aqui supracitados, os fatores religiosos possuem forte relação com as questões culturais e, como consequência, com próprio nível de crescimento e desenvolvimento econômico.

Outro fato que dever ser mencionado é a relação do protestantismo com a decisão de empreender, pois as igrejas protestantes que praticam a chamada teologia da prosperidade apresentaram crescimento particularmente acentuado do empreendedorismo (MARTES; RODRIGUES, 2004). Assim, com a finalidade de expor alguns estudos que analisaram empiricamente a relação entre o empreendedorismo e a religião, a próxima seção apresenta alguns resultados dos principais estudos.

\section{ESTUDOS EMPÍRICOS}

Serafim, Martes e Rodriguez (2012) desenvolveram um estudo com intuito de investigar os mecanismos de incentivo ao empreendedorismo proporcionado por organizações religiosas. Os autores apontam que o pertencimento às igrejas pode resultar na formação de capital social que permite a orientação para diversas dimensões econômicas e no reforço religioso à motivação econômica. Hoogendoorn, Rietveld e Van Stel (2016), também retratam sobre a importância do capital social desenvolvido por meio de atividades religiosas como efeitos benéficos ao desenvolvimento de atividades empreendedoras. Os autores desenvolveram um estudo empírico por meio de uma pesquisa transversal, utilizando dados de 30 países e concluíram que a religião está positivamente associada com a taxa de propriedade de negócios, ocorrendo por meio de aspectos internos da religiosidade, ou seja, crença e comportamento associado a crença.

Nunziata e Rocco (2016) desenvolveram um estudo com objetivo de verificar se o protestantismo favorece o empreendedorismo mais do que o catolicismo. $O$ 
estudo foi desenvolvido na Suíça e os autores colheram evidências de que o protestantismo está associado a uma propensão significativamente maior para o empreendedorismo do que o catolicismo, confirmando a hipótese de Laveleye (1985).Já analisando especificamente a religião protestante e a classificando em dois grupos: empregadores e empregados, Rietveld e Van Burg (2014) identificaram que quanto maior a crença de que o trabalho é uma atividade divina, maior é influência da religião como ação empreendedora, convergindo com os fundamentos teóricos apresentados por Enoque, Borges e Borges (2015). De acordo com Rietveld e Van Burg (2014) os empresários protestantes têm uma crença mais forte de que seu trabalho é divino. Para os empresários, a crença é de que seu trabalho é uma vocação divina. Além disso, eles são mais propensos a perceber um dever de agregar valor à sociedade por meio do seu trabalho.

Davidsson (1989) desenvolveu um estudo com intuito de ampliar o conhecimento a respeito do empreendedorismo, seu foco estava em identificar os determinantes do comportamento empreendedor. O estudo foi desenvolvido por meio de uma pesquisa empírica junto a uma amostra aleatória estratificada de pequenas empresas em quatro setores, complementados com dados de fontes externas. Os resultados apontam que os aspectos sociais têm forte relação com o comportamento empreendedor, principalmente em pequenas empresas em que a figura do empreendedor se traduz na própria estrutura de governança. Assim, fatores associados ao indivíduo como religião, estado civil, grau de instrução entre outros exercem influência significativa na decisão de empreender e no crescimento da firma.

Brockhaus (1982) teve interesse em identificar o que leva um indivíduo a ser um empreendedor. Para o autor, variáveis como sexo, idade, espaço geográfico e ramo de ocupação têm efeito significativo na formação do comportamento empreendedor. Já Reynolds (2005) elaborou um estudo com dados de diversos países em que o objetivo foi identificar os antecedentes e consequentes da criação de empresas, sobretudo o autor tinha forte interesse em observar como aspectos morais e éticos poderiam influenciar na motivação da criação de negócios. Os achados da pesquisa mostram diferenças significativas nos fatores motivadores da criação de empresas quando comparados países desenvolvidos e em desenvolvimento. Em países desenvolvidos é maior a taxa de empreendedorismo por oportunidade, enquanto que em países em desenvolvimento a taxa de empreendedorismo por necessidade é maior, as diferenças ainda se refletem quanto à idade, sexo, taxa de formalidade e informalidade eapoio financeiro.

Os trabalhos de Galbraith e Galbraith (2007) foram desenvolvidos com 23 países e tinham como objetivo examinar e testar a relação e interação entre religiosidade "intrínseca", atividade empresarial e crescimento econômico. Os resultados sugerem que a religiosidade está positivamente relacionada à atividade empreendedora e, consequentemente, com o crescimento econômico.

Em suma, é grande o número de estudos empíricos que buscaram analisar a influência da religião na atividade empreendedora. No entanto, conforme já apresentado no tópico de introdução deste trabalho, no Brasil, as pesquisas sobre essa temática ainda se encontram em estado incipiente.

\section{PROCEDIMENTOS METODOLÓGICOS}

Com os objetivos de verificar os fatores que contribuem para decisão de empreender e se existe alguma relação com a religião, a variável dependente 
representa ser ou não empreendedor e foi criada com base a definição de empreendedorismo firmada por Hoogendoorn, Rietveld e Van Stel ${ }^{8}$ (2016)

Nestes casos, a variável dependente é uma variável binária e, faz-se necessário a utilização de uma ferramenta metodológica que viabilize tal análise. Uma vez que a variável dependente é uma variável qualitativa, exige-se um modelo de regressão de resposta qualitativa, os quais são utilizados constantemente em várias áreas das ciências sociais (GUJARATI; PORTER, 2011).

Dessa forma, Ferreira Celso e Barbosa Neto (2012), elucidam que em modelos com variáveis contínuas relacionadas a atributos, as quais são utilizadas como variáveis explicativas, uma das melhores metodologias a serem aplicadas é a Regressão Logística, denominado Logit ${ }^{9}$, o qual associa apenas uma alternativa a cada conjunto de valores assumido pelas variáveis independentes. Pindyck e Rubinfeld (1998), ainda fundamentam que o Logit Binomial se trata de uma metodologia de seleção qualitativa, o qual possui a função de gerar respostas de procedimentos qualitativos como por exemplo a presença ou a ausência de uma determinada característica. Uma característica positiva da regressão logística binomial é que a variável dependente é binária tornando os pressupostos mais flexíveis e compreensíveis aos objetivos propostos (FAVERO, 2014).

Matematicamente, a regressão logística objetiva avaliar a probabilidade de "p" ocorrência de um determinado evento com base no comportamento de variáveis explicativas, sabendo-se que a chance de um evento é apresentada por (FAVERO, 2014). Dado os pressupostos anteriores, a equação que representa o modelo de regressão logística é apresentada abaixo:

$$
\ln (\text { chance })=Z=\alpha+\beta_{1} X_{1}+\beta_{2} X_{2}+\cdots+\beta_{n} X_{n}
$$

O qual, com algumas manipulações, chega-se a:

$$
p=\frac{1}{1+e^{-Z}}=\frac{1}{1+e^{-\left(\alpha+\alpha+\beta_{1} X_{1}+\beta_{2} X_{2}+\cdots+\beta_{n} X_{n}\right)}}
$$

Em que: "Z" é denominado por Logit; "p" por probabilidade estimada de ocorrência do evento de interesse; são as variáveis explicativas e os parâmetros do modelo. Destaca-se, ainda, que segundo Gujarati e Porter (2011), em modelos no qual a variável dependente é qualitativa, o objetivo é encontrar a probabilidade de que determinada ação ocorra, isto é, a probabilidade de a variável dependente transitar de 0 para 1. O modelo Logit se destaca das demais metodologias por ser facilmente interpretativo e versátil em referência aos regressores e seus efeitos e a possível interpretação como um modelo de escolha discreta (CRAMER; RIDDER, 1988).Com isso, a estimação do modelo consiste na transformação da equação anterior na que segue:

$$
L_{i}=\ln \left(\frac{P_{i}}{1-P_{i}}\right)=\beta_{1+} \beta_{2} X_{i_{+}} \mu_{i}
$$

\footnotetext{
${ }^{8}$ Em outras palavras, nos casos em que os indivíduos responderam trabalhar explorando o próprio negócio, a variável tomou valor "1" e nos demais, "0".

${ }^{9}$ Outros modelos de regressão foram testados, como o método dos Mínimos Quadrados Ordinários (MQO) e o modelo PROBIT e os resultados encontrados foram muito similares aos apresentados pela regressão logística.
} 
Embora a Equação (3) apresente uma relação importante, o modelo não possui fácil interpretação. De acordo com Cameron e Trivedi (2005), os efeitos marginais podem ser apresentados em termos das razões de chances, em outras palavras, pode ser definida como a probabilidade de determinado evento acontecer. Ou seja, é retirado o antilogaritmo dos coeficientes.

Assim, deve-se estimar os parâmetros do modelo, os estimadores de máxima verossimilhança para os parâmetros são os valores que maximizam o logaritmo da função de verossimilhança. A função de verossimilhança tem máximo, pois, sendo estritamente crescente (FERREIRA, 2012). Em relação à interpretação dos coeficientes, ao se aplicar o método de ganho marginal, Odds Ratio, faz-se necessário subtrair um e multiplicar por 100 (coeficiente-1)x100. Dessa forma, a próxima seção apresenta o banco de dados utilizado.

\section{Banco de Dados}

A base de dados utilizada foi construída por meio dos microdados ${ }^{10}$ do Censos Demográficos de 1991, 2000 e 2010, elaborado pelo IBGE. Os Censos Demográficos fornecem informações detalhadas sobre condições de moradia, famílias, renda, educação, emprego no Brasil permitindo o aprimoramento das pesquisas na área da Economia da Religião no Brasil. Outros estudos utilizam os Censos para explorar essa lacuna de pesquisa no país, tal como Bernardelli e Michellon (2018a), Bernardelli e Michellon (2018b), Bernardelli, Gomes e Michellon (2017) e Vieira (2013).

Os indivíduos foram selecionados na presente amostra de acordo com as especificidades das variáveis selecionadas, isto é, foram selecionadas apenas os indivíduos que responderam às perguntas utilizadas pelo presente estudo. Dessa forma, foram selecionadas pessoas que responderam à questão relacionada ao tipo de vínculo empregatício, setor de atividade, pessoas entre 18 a 65 anos, e pessoas que responderam questões relacionadas ao nível de escolaridade. Para ilustrar a quantidade de observações descartadas e a quantidade de observações restantes, o Tabela 1 apresenta o procedimento realizado.

Tabela 1. Detalhes iniciais sobre a amostra

\begin{tabular}{cccc}
\hline Dados & Amostra total & Amostra descartada & Amostra remanescente \\
\hline 1991 & 17.045 .710 & -8.897 .535 & 8.148 .175 \\
2000 & 20.274 .314 & -14.790 .374 & 5.483 .940 \\
2010 & 20.635 .472 & -13.772 .582 & 6.862 .890 \\
\hline
\end{tabular}

Fonte: Elaborado pelos autores a partir dos dados dos Censos Demográficos 1991, 2000 e 2010.

A Tabela 1 apresenta a quantidade de informação inicial e as observações descartadas pela não informação dos dados. Esse procedimento é consistente do ponto de vista econométrico ao se considerar o alto número de observações.

Para classificação das religiões, as mesmas foram divididas de acordo com a classificação de religiões dos Censos Demográficos ${ }^{11}$. Desse modo, a próxima seção detalha de forma minuciosa o modelo empírico aplicado. A utilização deste banco de

\footnotetext{
${ }^{10}$ Consistem no menor nível de desagregação dos dados de uma pesquisa e retratam o conteúdo dos questionários, preservando o sigilo estatístico com vistas a não individualização das informações (IBGE, 2017).

${ }^{11} \mathrm{O}$ anexo 1 apresenta a classificação utilizada.
} 
dados para a temática é pouco utilizada, o que potencializa o impacto deste estudo. Nas palavras de Decol (1999), embora a religião se mostre como um tema central sociológico e até mesmo econômico, poucos estudos são realizados no Brasil acompanhando informações quantitativas e pertinentes dos Censos Demográficos. Ainda para Decol (1999), o fato é tão mais paradoxal quando se lembra que o censo do IBGE inclui uma pergunta sobre religião desde 1940.

Sobre a definição de empreendedor utilizou-se: (i) as pessoas que trabalhavam explorando seu próprio empreendimento, sozinha ou com sócio, sem ter empregado. ainda que contando com ajuda de trabalhador não remunerado e (ii) pessoas que trabalhavam explorando o seu próprio empreendimento com, pelo menos, um empregado $^{12}$. As variáveis explicativas selecionadas para definir ser ou não empreendedor estão no Quadro 1.

Quadro 1. Descrição das variáveis utilizadas na pesquisa

\begin{tabular}{|ll|}
\hline \multicolumn{1}{|c|}{ Variável } & \multicolumn{1}{c|}{ Descrição } \\
\hline Empreendedor & Se empregador (binária) \\
P1(Referência) & Se protestante (binária) \\
H2 & Menor ou igual a 7 anos de estudo (binária) \\
H3 & De 8 a 10 anos de estudo (binária) \\
H4 & De 11 a 14 anos de estudo (binária) \\
NORTE & Acima de 15 anos de estudo (binária) \\
Nordeste & Se reside na região Norte (binária) \\
Sul & Se reside na região Nordeste (binária) \\
Sudeste & Se reside na região Sul (binária) \\
Centro-Oeste & Se reside na região Sudeste (binária) \\
NãoBranco & Se reside na região Centro-Oeste (binária) \\
Imigrante & Se cor não branca (binária) \\
Homem & Se é imigrante (binária) \\
Casado & Se é do sexo masculino (binária) \\
Idade & Se é casado (binária) \\
Idade2 & Idade em anos \\
Agricultura & Idade ao quadrado \\
Indústria & Se atua na agricultura (binária) \\
Comércio & Se atua na Indústria (binária) \\
Social & Se atua no comércio (binária) \\
Outros & Se atua no setor social (binária) \\
\hline
\end{tabular}

Fonte:Elaborado pelos autores a partir dos dados dos Censos Demográficos de 1991, 2000 e 2010.

As varáveis selecionadas são encontradas na literatura como determinantes do comportamento empreendedor. Diversos autores apontam o nível de escolaridade/instrução, idade, religião, sexo, estado civil e ambiente como fatores que possuem significativa relação com o comportamento empreendedor (DAVIDSSON,1989; BROCKHAUS, 1982; REYNOLDS, 2005; CARSWELL; ROLLAND, 2007; GALBRAITH; GALBRAITH, 2007; AL-GHAZALI, 2013). Assim, o próximo tópico traz os resultados e discussões do estudo. Em relação a classificação das atividades, o Anexo 2 apresenta detalhadamente o utilizado.

\section{RESULTADOS E DISCUSSÕES}

A partir das fundamentações teóricas apresentadas anteriormente, torna-se evidente que existe um denso arcabouço teórico que aponta a importância do

12 Os indivíduos selecionados possuem idade entre 18 e 65 anos, e realizam algum tipo de atividade profissional. 
aumento da população empreendedora e sua relação para o crescimento e o desenvolvimento econômico do país. Com a finalidade de realizar uma análise inicial sobre as variáveis utilizadas neste estudo, a Tabela 2 apresenta a variação das variáveis utilizadas.

Tabela 2. Média e variação das variáveis utilizadas na pesquisa

\begin{tabular}{lccccc}
\hline \multicolumn{1}{c}{ VARIÁVEL (\%) } & MÉDIA 1991 & MÉDIA 2000 & MÉDIA 2010 & $\boldsymbol{\Delta}(\mathbf{\%}) \mathbf{( 9 1 - 0 0 )}$ & $\boldsymbol{\Delta}(\mathbf{\%}) \mathbf{( 0 0 - 1 0 )}$ \\
\hline Empreendedor & 19,96 & 31,72 & 28,23 & 58,94 & $-10,99$ \\
P & 8,74 & 14,24 & 20,06 & 63,00 & 40,84 \\
H1 (Referência) & 74,09 & 53,27 & 42,50 & $-28,09$ & $-20,22$ \\
H2 & 12,30 & 17,71 & 22,21 & 44,00 & 25,36 \\
H3 & 10,65 & 22,23 & 27,35 & 108,76 & 23,03 \\
H4 & 2,96 & 6,78 & 7,94 & 129,00 & 17,12 \\
Norte & 5,73 & 5,38 & 6,33 & $-6,10$ & 17,65 \\
Sul & 16,27 & 18,73 & 21,31 & 15,10 & 13,79 \\
Sudeste & 44,61 & 47,66 & 42,46 & 6,84 & $-10,91$ \\
Nordeste (Referência) & 26,72 & 20,76 & 22,23 & $-22,30$ & 7,08 \\
Centro-Oeste & 6,67 & 7,47 & 7,67 & 11,93 & 2,66 \\
Não Branco & 47,17 & 41,47 & 48,28 & $-12,08$ & 16,43 \\
Imigrante & 0,58 & 0,42 & 0,21 & $-26,87$ & $-49,60$ \\
Masculino & 48,94 & 63,82 & 60,22 & 30,39 & $-5,63$ \\
Casado & 65,73 & 47,77 & 43,11 & $-27,32$ & $-9,77$ \\
Idade & 35,62 & 34,73 & 36,31 & $-2,50$ & 4,55 \\
Agricultura & 16,19 & 18,37 & 19,67 & 13,52 & 7,04 \\
Indústria & 14,20 & 21,61 & 21,03 & 52,20 & $-2,70$ \\
Comércio & 23,48 & 47,41 & 43,20 & 101,88 & $-8,87$ \\
Social & 1,93 & 8,92 & 8,27 & 362,76 & $-7,28$ \\
Outros & 1,05 & 2,36 & 2,09 & 125,52 & $-11,35$ \\
Sem info de atividade & 43,16 & 1,33 & 5,74 & $-96,92$ & 331,58 \\
\hline
\end{tabular}

Fonte: Elaborado pelos autores a partir dos dados dos Censos Demográficos 1991, 2000 e 2010. Notas: (i) a média das variáveis binárias representam a proporção de pessoas com determinada característica; (ii) o $\Delta$ significa variação.

Os valores encontrados para a variável "Empreendedor" representam a proporção de empregadores em relação à amostra total. De maneira geral, nota-se que houve uma substancial elevação dos empreendedores no Brasil entre o período de 1991 a 2000, mas reduziu entre o período posterior, entre 2000 a 2010 . Uma das hipóteses levantadas na literatura para explicar este movimento é que a alta formalização do trabalho presenciado no Brasil, entre os anos de 2000 a 2010, possivelmente reduziu o estímulo ao empreendedorismo por exploração do trabalho próprio, utilizado como proxy neste estudo. A mesma visão é compartilhada por Reynolds (2005), ao apontar que a taxa de empreendedorismo por necessidade está associada ao nível de empregabilidade do país, pois quanto menor a oportunidade de emprego, maior é o estimulo ao empreendedorismo.

Em relação ao comportamento das variáveis que representam o nível de instrução, H1, H2, H3 e H4, que retratam o nível de instrução da amostra, notou-se um leve acréscimo significativo no nível educacional, sendo resultado de uma preocupação crescente das autoridades públicas. De acordo Mont'alvão Neto (2014), fatores como a redução do tamanho das famílias e elevação dos níveis de saúde e nutrição dos estudantes contribuíram fundamentalmente na elevação dos níveis educacionais, mas fundamentalmente nos níveis básicos. Outra importante 
constatação foi o envelhecimento da população brasileira, o que confirma estudos como os de Alves (2014) e De Mello Moreira (2014).

Em relação à religião, nota-se uma expressiva alteração na proporção das protestantes no período, tal como ressaltado por Bernardelli e Michellon (2018a) que identificou uma elevação da proporção da população cristã-protestante de 15,55 pontos percentuais, enquanto a proporção da população católica declinou aproximadamente 24,10 de 1980 a 2010 .

Nota-se, também, a partir dos valores encontrados na distribuição dos setores produtivos, que não houve relevante alteração no período de 2000 a 2010, diferentemente do período entre 1991 a 2000, sinalizando uma significativa alteração na organização do mercado de trabalho posterior a estabilização de preços. De forma complementar, a Tabela 3 apresenta com maiores detalhes o banco de dados utilizado.

Tabela 3. Desvio padrão, mínimo e máximo das variáveis utilizadas no modelo

\begin{tabular}{|c|c|c|c|c|c|c|c|c|c|}
\hline & \multicolumn{3}{|c|}{1991} & \multicolumn{3}{|c|}{2000} & \multicolumn{3}{|c|}{2010} \\
\hline VARIÁVEL & DesvPad & Min & Max & DesvPad & Min & Max & DesvPad & Min & Max \\
\hline Empreendedor & 0,40 & 0 & 1 & 0,47 & 0 & 1 & 0,45 & 0 & 1 \\
\hline$P$ & 0,28 & 0 & 1 & 0,35 & 0 & 1 & 0,33 & 0 & 1 \\
\hline $\mathrm{H} 1$ & 0,44 & 0 & 1 & 0,50 & 0 & 1 & 0,49 & 0 & 1 \\
\hline $\mathrm{H} 2$ & 0,33 & 0 & 1 & 0,38 & 0 & 1 & 0,42 & 0 & 1 \\
\hline H3 & 0,31 & 0 & 1 & 0,42 & 0 & 1 & 0,45 & 0 & 1 \\
\hline $\mathrm{H} 4$ & 0,17 & 0 & 1 & 0,25 & 0 & 1 & 0,27 & 0 & 1 \\
\hline Norte & 0,23 & 0 & 1 & 0,23 & 0 & 1 & 0,24 & 0 & 1 \\
\hline Sul & 0,37 & 0 & 1 & 0,39 & 0 & 1 & 0,41 & 0 & 1 \\
\hline Sudeste & 0,50 & 0 & 1 & 0,50 & 0 & 1 & 0,49 & 0 & 1 \\
\hline Nordeste & 0,44 & 0 & 1 & 0,41 & 0 & 1 & 0,42 & 0 & 1 \\
\hline Centro-Oeste & 0,25 & 0 & 1 & 0,26 & 0 & 1 & 0,27 & 0 & 1 \\
\hline Não Branco & 0,50 & 0 & 1 & 0,49 & 0 & 1 & 0,50 & 0 & 1 \\
\hline Imigrante & 0,08 & 0 & 1 & 0,06 & 0 & 1 & 0,05 & 0 & 1 \\
\hline Masculino & 0,50 & 0 & 1 & 0,48 & 0 & 1 & 0,49 & 0 & 1 \\
\hline Casado & 0,47 & 0 & 1 & 0,50 & 0 & 1 & 0,50 & 0 & 1 \\
\hline Idade & 12,93 & 18 & 65 & 11,25 & 18 & 65 & 11,75 & 18 & 65 \\
\hline Agricultura & 0,37 & 0 & 1 & 0,39 & 0 & 1 & 0,40 & 0 & 1 \\
\hline Indústria & 0,35 & 0 & 1 & 0,41 & 0 & 1 & 0,41 & 0 & 1 \\
\hline Comércio & 0,42 & 0 & 1 & 0,50 & 0 & 1 & 0,49 & 0 & 1 \\
\hline Social & 0,14 & 0 & 1 & 0,29 & 0 & 1 & 0,33 & 0 & 1 \\
\hline Outros & 0,10 & 0 & 1 & 0,15 & 0 & 1 & 0,14 & 0 & 1 \\
\hline Sem informação & 0,50 & 0 & 1 & 0,11 & 0 & 1 & 0,23 & 0 & 1 \\
\hline
\end{tabular}

Fonte:Elaborado pelos autores a partir dos dados dos Censos Demográficos 1991, 2000 e 2010.

Nota: as variáveis que estão representadas com valor mínimo de 0 e máximo de 1 são variáveis dicotômicas. que assumem estes dois valores.

Por meio da Tabela 3, nota-se através do desvio-padrão que há uma relevante disparidade entre os dados, isto é, há uma grande heterogeneidade entre os indivíduos. Isso ocorre porque se trata de uma análise nacional, relacionando pessoas de todos os estados brasileiros, retratando uma desigualdade perceptível no Brasil e apresentada por diversos autores como Furtado (1983), Hoffmann (1998), Hoffmann (2001).

Em relação à variável de religião, os dados contidos na Tabela 3 confirmam as análises de Neri e Melo (2011) e Mariano (2013), que há grande diversidade religiosa entre as regiões do Brasil e que se trata de uma das variáveis socioeconômicas que mais se alteraram nos últimos anos. Esta informação é mais um apontamento que reforça a importância de se analisar o impacto econômico advindo das alterações ocorridas no campo religioso brasileiro 
Em especial, considerando a variável de instrução, de acordo com Ney, De Souza e Ponciano (2015),trata-se de um sério problema a ser combatido no país é em relação a desigualdade de oportunidade educacional que, ao dificultar o acesso da população com menor renda a níveis elevados de educação, não apenas restringe a expansão do ensino, mas também causa a heterogeneidade educacional ${ }^{13}$. Desse modo, a Tabela 4 mostra os resultados da regressão logística.

Tabela 4. Resultados da regressão logística

\begin{tabular}{|c|c|c|c|c|}
\hline VARIÁVEIS & 1991 & 2000 & 2010 & Empilhado \\
\hline \multirow{2}{*}{$\mathrm{P}(\%)$} & $1,103^{* * *}$ & $1,082^{\star \star \star}$ & $1,020^{* * *}$ & $1,033^{* * *}$ \\
\hline & $(25,30)$ & $(27,72)$ & $(8,508)$ & $(20,38)$ \\
\hline H2 (\%) & $\begin{array}{l}1,028^{* * *} \\
(8,025)\end{array}$ & $\begin{array}{c}1,051^{\text {***}} \\
(17,63)\end{array}$ & $\begin{array}{c}1,046^{* * \star} \\
(18,13)\end{array}$ & $\begin{array}{l}1,053^{\star * *} \\
(31,92)\end{array}$ \\
\hline \multirow{2}{*}{ H3 (\%) } & $1,099^{* * *}$ & $1,084^{* * *}$ & $1,048^{* * *}$ & $1,070^{* * *}$ \\
\hline & $(26,32)$ & $(29,38)$ & $(19,71)$ & $(43,23)$ \\
\hline \multirow{2}{*}{$\mathrm{H} 4$ (\%) } & $1,748^{* * *}$ & $1,933^{* * *}$ & $1,654^{* * *}$ & $1,850^{* * *}$ \\
\hline & $(100,3)$ & $(151,5)$ & $(133,9)$ & $(246,0)$ \\
\hline \multirow{2}{*}{ Norte (\%) } & $1,404^{* * *}$ & $1,250^{* * *}$ & $1,331^{* * *}$ & $1,333^{* * *}$ \\
\hline & $(72,46)$ & $(49,32)$ & $(74,33)$ & $(118,0)$ \\
\hline \multirow{2}{*}{ Sul (\%) } & $0,651^{\text {*** }}$ & $0,721^{\text {*** }}$ & $0,804^{* * *}$ & $0,755^{* * *}$ \\
\hline & $(-124,8)$ & $(-100,1)$ & $(-76,75)$ & $(-157,5)$ \\
\hline \multirow{2}{*}{ Sudeste (\%) } & $0,453^{* * *}$ & $0,529^{* * *}$ & $0,577^{* * *}$ & $0,546^{* * *}$ \\
\hline & $(-283,4)$ & $(-236,1)$ & $(-223,7)$ & $(-404,5)$ \\
\hline \multirow{2}{*}{ Centro-Oeste (\%) } & $0,653^{* * *}$ & $0,673^{* * *}$ & $0,728^{* \star *}$ & $0,712^{* * \star}$ \\
\hline & $(-96,24)$ & $(-93,76)$ & $(-83,87)$ & $(-144,3)$ \\
\hline \multirow{2}{*}{ Não Branco (\%) } & $0,740^{* * *}$ & $0,730^{* * *}$ & $0,716^{* * *}$ & $0,727^{* * *}$ \\
\hline & $(-127,0)$ & $(-141,9)$ & $(-167,3)$ & $(-257,1)$ \\
\hline \multirow{2}{*}{ Imigrante (\%) } & $1,741^{* * *}$ & $1,732^{\star * *}$ & $2,052^{* * *}$ & $1,772^{* * *}$ \\
\hline & $(42,72)$ & $(37,56)$ & $(39,94)$ & $(70,59)$ \\
\hline \multirow{2}{*}{ Masculino (\%) } & $1,781^{* * *}$ & $1,615^{\star * *}$ & $1,244^{* * *}$ & $1,649^{* * *}$ \\
\hline & $(215,0)$ & $(212,1)$ & $(110,7)$ & $(390,1)$ \\
\hline \multirow{2}{*}{ Casado (\%) } & $1,546^{* * *}$ & $1,302^{\star * *}$ & $1,251^{* * *}$ & $1,361^{* * *}$ \\
\hline & $(177,8)$ & $(123,6)$ & $(115,8)$ & $(258,8)$ \\
\hline \multirow{2}{*}{ Idade (\%) } & $1,036^{* * *}$ & $1,049^{* * *}$ & $1,044^{* * *}$ & $1,040^{* * *}$ \\
\hline & $(367,1)$ & $(495,6)$ & $(512,2)$ & $(779,7)$ \\
\hline \multirow{2}{*}{ Indústria (\%) } & $0,561^{* * *}$ & $0,589^{* * *}$ & $0,512^{* * *}$ & $0,544^{* * *}$ \\
\hline & $(-191,8)$ & $(-172,3)$ & $(-245,3)$ & $(-363,2)$ \\
\hline \multirow{2}{*}{ Comércio (\%) } & $1,088^{* * *}$ & $0,818^{\star * *}$ & $0,553^{* * *}$ & $0,771^{\text {*** }}$ \\
\hline & $(31,08)$ & $(-73,51)$ & $(-244,6)$ & $(-175,2)$ \\
\hline \multirow{2}{*}{ Social (\%) } & $0,427^{* * *}$ & $0,149^{* * *}$ & $0,120^{* * *}$ & $0,169^{* * *}$ \\
\hline & $(-112,3)$ & $(-333,0)$ & $(-396,2)$ & $(-518,6)$ \\
\hline Outros (\%) & $\begin{array}{c}0,212^{* * *} \\
(-133,6)\end{array}$ & $\begin{array}{c}0,153^{* * *} \\
(-198,0)\end{array}$ & $\begin{array}{c}0,165^{* * *} \\
(-208,2)\end{array}$ & $\begin{array}{c}0,172^{\text {*** }} \\
(-315,3)\end{array}$ \\
\hline \multirow{2}{*}{ Sem_info (\%) } & $0,00287^{* * *}$ & $1,292^{* * *}$ & $0,511^{* * *}$ & $0,0548^{* * *}$ \\
\hline & $(-443,6)$ & $(31,16)$ & $(-157,6)$ & $(-952,3)$ \\
\hline \multirow{2}{*}{ Constant } & $0,146^{* * *}$ & $0,115^{* * *}$ & $0,157^{* * *}$ & $0,141^{* * *}$ \\
\hline & $(-373,8)$ & $(-432,5)$ & $(-405,2)$ & $(-712,4)$ \\
\hline Observações & 8.148 .175 & 5.483 .940 & 6.862 .890 & 20.495 .005 \\
\hline Pseudo R-squared & 0,251 & 0,159 & 0,133 & 0,163 \\
\hline
\end{tabular}

Fonte: Elaborado pelos autores a partir dos dados dos Censos Demográficos de 1991.2000 e 2010. Notas: (i) Estatística $z$ em parênteses; ${ }^{* *} p<0.01 .{ }^{* *} p<0.05 .{ }^{*} p<0.1$ (ii) As variáveis "H1" e "Nordeste" foram omitidas porque retratam as variáveis de referência da regressão.

Os resultados apresentados na Tabela 4 retratam relações importantes, tal como evidenciado no Quadro 1, o número de observações que atenderam os critérios

${ }^{13}$ Com a finalidade de combater as diferenças nos níveis de educação entre as regiões brasileiras, diversas políticas públicas estão sendo empregadas, como a base nacional comum curricular (BRASIL, 2017). 
da análise foi de 8.148.178; 5.483 .940 e 6.862.890, respectivamente, para os anos de 1991, 2000 e 2010, totalizando 20.495 .005 observações. Os valores encontrados para o Pseudo $\mathrm{R}^{2}$ são elevados para uma análise com microdados.

Em relação à principal variável de interesse, a religião, os resultados mostram um impacto positivo entre o protestantismo e a característica empreendedora, em que o indivíduo de religião protestante, apresenta uma razão de chances maior em ser empreendedor de, aproximadamente, $10,3 \%, 8,2 \%$ e $2 \%$, respectivamente em relação a 1991, 2000 e 2010 e 3,3\% em relação a amostra total, mostrando que a religião é um fator que deve ser considerado ao se analisar os determinantes do empreendedorismo, fato este que vai ao encontro das pesquisas de Serafim, Martes e Rodrigues (2012), Rietveld e Van Burg (2014) e de Enoque, Borges e Borges (2015).

Assim, os resultados mostram uma relação positiva, indicando que o aumento de adeptos da religião cristã protestante no Brasil pode ter influenciado positivamente para o empreendedorismo no país.

No entanto, a contínua redução desse coeficiente no período analisado, pode ser resultado da secularização, que é retratado por Oliveira e Raiher (2018) como um processo através do qual a religião perde a sua influência sobre as variadas esferas da vida social, reduzindo a aderência de suas práticas e na influência na sociedade. Ou seja, à medida que se reduz a influência da religião na vida dos indivíduos, diminui o impacto na decisão de ser ou não empreendedor.

Em relação aos coeficientes das variáveis, nota-se que um aumento no grau de instrução impacta positivamente na razão de chance de empreender. Sendo que o último nível educacional "H4", considerando a especificação com os três períodos, indica que as pessoas com mais de 15 anos de escolaridade possuem $85 \%$ de chances de empreender a mais em relação as pessoas de 0 a 7 anos de escolaridade, estabelecendo um forte vínculo entre nível de instrução e empreendedorismo, assim como fundamentado por Davidsson (1989); Brockhaus (1982); Reynolds (2005); Carswell e Rolland (2007); Galbraith e Galbraith (2007) e Al-ghazali (2013).

Mais especificamente no que concerne às razões de chance, considerando a especificação econométrica que contempla os três períodos do estudo, os valores retratados pela Tabela 4 apontam a probabilidade de o indivíduo ser empreendedor aumenta, aproximadamente, 2,8\%, 9,9\% e $74 \%$, respectivamente para os níveis $\mathrm{H} 2$, $\mathrm{H} 3$ e $\mathrm{H} 4$ de escolaridade, em relação ao nível omitido $\mathrm{H} 1$. O fato é que quanto maior for o grau de escolaridade, maior é a capacidade de busca por novas oportunidades, nesse caso, o empreendedorismo em si (MACHADO et al., 2016).

Já no que se refere às localidades, as regiões, Norte, Sul, Sudeste e CentroOeste, apresentaram, 33\%, $-24,5 \%, 46,4 \%$ e $-28.8 \%$ chances de empreender em relação a região omitida Nordeste. A região que se evidencia maior probabilidade de se empreender é o Norte, constatação que é justificada pela escolha da proxy de empreendedorismo que está próxima da de empreender por necessidade. Esse resultado também pode ser um indicativo do baixo número de trabalhos formais encontrado nessa região como apontam os estudos de Corseuil et al. (2015) e Guimarães e Silva (2017).

Já a variável não branco apontou que as chances dos não brancos empreenderem é de $-27,3 \%$, em relação aos brancos. Resultados semelhantes já foram apontados no estudo de Paixão (2003) em que, por exemplos, os negros, apesar de apresentam as mesmas dificuldades de outros empreendedores no Brasil, as questões étnicas influenciam na dinâmica dos empreendimentos empresarias realizadas por eles, especialmente a relacionada à captação de recursos, relação com 
fornecedores, clientes e com funcionários. O estudo de Oliveira et al. (2013) evidenciou que a maior parte da composição dos empreendedores são da raça branca para todas as grandes regiões do país.

Referente à variável imigrante, apontou que um imigrante possui $77 \%$ de chances a mais de empreender do que um brasileiro, segundo Cruz et al. (2017) a justificativa para isso deve ao fato que as provisões de capital dos empreendedores imigrantes e suas identidades sociais têm influência sobre as escolhas de empreender.

Estar casado apresenta uma relação positiva, ou seja, a probabilidade de empreender é de $36,10 \%$, confirmando os resultados do estudo de Araújo e Marques Junior (2018), em que a maioria dos empreendedores são casados. As pessoas do sexo masculino também possuem uma chance superior, de $64,9 \%$, corroborando com a pesquisa Oliveira et al. (2013) em que os autores evidenciaram que a maior parte da composição dos empreendedores são do gênero masculino para todas as grandes regiões do país.

Em relação a idade, a probabilidade de se empreendera partir dos 18 anos, se eleva em aproximadamente 4\%, conforme Lüdke e Bugs (2017), no Brasil, os jovens sonham em ter seu próprio negócio, justificando a alta taxa de empreendedores entre 18 a 34 anos

As demais especificações econométricas, isto é, em relação aos períodos de 1991, 2000 e 2010, retratam resultados semelhantes aos da especificação com todas as variáveis, resultado que indica que o comportamento dessas variáveis parece permanecer o mesmo ao longo do tempo.

\section{CONSIDERAÇÕES FINAIS}

Com base nos fundamentos da importância do empreendedorismo para o desenvolvimento econômico do Brasil, este trabalho objetivou analisar alguns fatores que contribuem para a decisão de empreender dos indivíduos. A definição de empreendedorismo utilizada, como a capacidade de criar empreendimentos, possibilita uma associação a traços e habilidades específicas do indivíduo que propicia a criação de negócios, os quais podem estar associados com a religião. Nesse sentido, o presente estudo encontrou resultados relevantes.

Os resultados reforçam a importância de fatores como instrução, idade, casamento, atividade de trabalho e região, corroborando para a literatura já existente. Além disso, mostra que a religião também é uma variável importante na decisão de ser ou não empreendedor. Especificamente sobre os coeficientes encontrados para a variável ser ou não protestante, mostra um coeficiente significativo em todas as especificações econométricas apresentadas. Isso indica que a ética regida pela religião protestante pode atenuar as adversidades encontradas pelos empregadores e os riscos serem diluídos pela crença que os problemas serão superados.

Este resultado é relevante do ponto de vista econômico, em virtude da significativa alteração no campo religioso brasileiro que vem ocorrendo desde 1980, em que houve um crescimento da proporção de protestantes no Brasil superior a $250 \%$, apontamentos de que isso possa ter contribuído para a disseminação do empreendedorismo no país.

Contudo, embora as razões de chances tenham sido positiva em todas os períodos analisados, os coeficientes seguem uma tendência de redução, indicativo de que a secularização da sociedade pode estar reduzindo as diferenças entre os 
protestantes e não protestantes e, consequentemente, exercendo menor impacto na decisão de ser ou não empreendedor.

As limitações encontradas nesse estudo estão relacionadas a frequência religiosa da população e a uma melhor proxy para empreendedorismo, em virtude de tais informações não estarem disponíveis nos Censos Demográficos. Para futuras pesquisas, recomenda-se a divisão dos grupos de protestantes, em tradicionais pentecostais, dado a distinção no comportamento destas religiões. Além disso, uma relação importante a ser considerada na presente análise é a análise espacial. Nesse caso, uma maior proporção de empreendedores em um município poderia afetar o seu envoltório, ou melhor, municípios empreendedores afetam positivamente seu envoltório.

\section{REFERÊNCIAS}

AL-GHAZALI. B. M.; YUSOFF. R. M.; SADI. MUHAMMAD A. Women Entrepreneurs in Bahrain: Motivations and Barriers. Jurnal Teknologi. [s.I.]. v. 64. n. 2. p.139-143. 26 set. 2013.

ALVES. J. E. D. Transição demográfica. transição da estrutura etária e envelhecimento. Revista Portal de Divulgação. n. 40. 2014.

ARAÚJO, F. S. G.; MARQUES JUNIOR, S. M. Empreendedorismo e turismo: caracterização do perfil empreendedor do setor de turismo no rio grande do norte. Revista Turismo: estudos e práticas, v. 7, n. 1, 2018.

BARRO. R. J.; MCCLEARY. R. M. Religion and Economic Growth across Countries. American Sociological Review. [s.I.]. v. 68. n. 5. p.760-814. 2003.

BERNARDELLI, L. V.; GOMES, C. E.; MICHELLON, E. Religião e desenvolvimento econômico: uma análise para o brasil à luz do catolicismo e protestantismo. Revista de Economia Mackenzie, v. 13, n. 1, 2017.

BERNARDELLI, L. V.; MICHELLON, E. O Impacto da Religião no Crescimento Econômico: Uma Análise Empírica para o Brasil em 1991, 2000 e 2010. Estudos Econômicos (São Paulo), v. 48, n. 3, p. 489-523, 2018 a.

BERNARDELLI, L. V.; MICHELLON, E. A religião e o crescimento econômico: uma análise para o paraná de 2000 e 2010. Revista Paranaense de DesenvolvimentoRPD, v. 39, n. 134, 2018b.

BOSWELL. T. E. A Split Labor Market Analysis of Discrimination Against Chinese Immigrants. American Sociological Review. 51. p.352-71. 1986.

BROCKHAUS. R. H. The psychology of the entrepreneur. In: Kent. Calvin A.; Sexton. Donald L.; Smilor. Raymond W. (Ed.). Encyclopedia of entrepreneurship. Englewood Cliffs. 1982.

CAMERON. A. C.; TRIVEDI. P. K. Microeconometrics:methods and application.Cambridge: Cambridge University Press. 2005. 1058 p. 
CARSWELL. P.; ROLLAND. D. Religion and entrepreneurship in New Zealand. Journal of Enterprising Communities: People and Places in the Global Economy. [s.I.]. v. 1. n. 2. p.162-174. 5 jun. 2007.

CORSEUIL, C. H.; REIS, M. C.; BRITO, A. S. Critérios de classificação para ocupação informal: consequências para a caracterização do setor informal e para a análise de bem-estar no Brasil. Estudos Econômicos, v. 45, n. 1, p. 5-31, 2015.

COSTA. P. da; WOLF. S. M.; RIBEIRO. T. V. A. Empreendedorismo e educação empreendedora: confrontação entre a teoria e prática. Revista de Ciências da Administração. Florianópolis. p. 09-29. jan. 2006.

CRAMER. J.s.; RIDDER. G. The Logit Model in Economics. Statistica Neerland. [s.I.]. v. 42. n. 4. p.297-314. 1988.

CRUZ, E. P.; FALCÃO, R. P. Q.; BARRETO, C. R. Estudo exploratório do empreendedorismo imigrante brasileiro em Pompano Beach e Orlando - EUA, Gestão \& Planejamento, n. 1, v. 18, p. 37-54.

DAVIDSSON. P. Continued Entrepreneurship and Small Firm Growth. Stockholm: The Economic Research Institute. 1989.

DE MELLO MOREIRA. M. O envelhecimento da população brasileira: intensidade. feminização e dependência. Revista Brasileira de Estudos de População. v. 15. n. 1. p. 79-94. 2014.

DE OLIVEIRA. L.; RAIHER. A. P. A NÃO RELIGIOSIDADE AO LONGO DO BRASIL: SUA EVOLUÇÃO E SEUS DETERMINANTES. Economia \& Região. v. 5. n. 2. p. 103-127. 2018.

DECOL, R. D. Mudança religiosa no Brasil: uma visão demográfica. Revista Brasileira de Estudos de População, v. 16, n. 1/2, p. 121-137, 1999.

DORNELAS. J. C. A. Empreendedorismo corporativo: como ser empreendedor. inovar e se diferenciar em organizações estabelecidas. Rio de Janeiro: Elsevier. 2003.

ECKHARDT. J. Opportunities and Entrepreneurship. Journal of Management. [s.I.]. v. 29. n. 3. p.333-349. jun. 2003.

ENOQUE. A. G.; BORGES. A. F.; BORGES. J. F. "Além do que se Vê...”: Análise do Conceito Weberiano de Vocação à Luz da Dinâmica do Empreendedorismo Religioso. Organizações \& Sociedade (Online). v. 22. p. 505-520. 2015.

FAVERO. L. P. Métodos Quantitativos com Stata. Rio de Janeiro: Elsevier. 2014.

FERREIRA. A. Regressão Logística. Universidade do Estado do Rio de Janeiro: Instituto Politécnico: Departamento de Modelagem Computacional. 16. 2012.

FERREIRA. M. A. M; CELSO. A.S. S; BARBOSA NETO. J.E. Aplicação do modelo logit binominal na análise do risco de crédito em instituições bancárias. $\boldsymbol{R} \boldsymbol{n}$. [s.l.]. v. 17. n. 1. p.38-57. 14 jun. 2012. 
FURTADO. C. Teoria e Política do Desenvolvimento Econômico. 8. ed. São Paulo: Nacional. 1983.

GAARDER. J; HELLERN. V; NOTAKER. H. O Livro das Religiões. São Paulo: Companhia das Letras. 2005.

GALBRAITH. C. S.; GALBRAITH. D. M.. An empirical note on entrepreneurial activity. intrinsic religiosity and economic growth. Journal Of Enterprising Communities: People and Places in the Global Economy. [s.I.]. v. 1. n. 2. p.188-201. 5 jun. 2007.

GARTNER. W. B.; "Who is an Entrepreneur?" is the Wrong Question. University of Illinois at Urbana-Champaign's Academy for Entrepreneurial Leadership Historical Research Reference in Entrepreneurship. 1988.

GUIMARÃES, C.; SILVA, J. R. Turismo e geração de empregos formais: Um estudo sobre o Brasil e suas regiões. Revista Turismo \& Desenvolvimento, v. 1, n. 27/28, p. 1273-1286, 2018.

GUJARATI. D. N; PORTER. D. C. Econometria Básica. 5 ed. Porto Alegre: Bookman. 2011.

HOFFMANN. R. A distribuição de renda no Brasil no período 1993-99. Campinas: Unicamp. IE. 2001.

HOFFMANN. R. Distribuição de renda - Medidas de desigualdade e pobreza. São Paulo: Editora da Universidade de São Paulo. 1998.

HOOGENDOORN. B.; RIETVELD. C. A.; VAN STEL. A. Belonging. believing. bonding. and behaving: the relationship between religion and business ownership at the country level. Journal of Evolutionary Economics. [s.I.]. v. 26. n. 3. p.519-550. 2016.

KORTT, Michael A.; DOLLERY, Brian. Religion and the rate of return to human capital: evidence from Australia. Applied Economics Letters, v. 19, n. 10, p. 943-946, 2012.

KORTT, Michael A.; DOLLERY, Brian; GRANT, Bligh. The relationship between religious affiliation and returns to human capital for women. Economic Papers: A journal of applied economics and policy, v. 32, n. 3, p. 395-404, 2013.

LAVELEYE. Do Futuro dos Povos Católicos: Estudo de Economia Social. 2 ed. Tradução por Dr. Miguel Vieira Ferreira. São Paulo: Casa Editora Presbiteriana. 1985.

LÜDKE, F. E.; BUGS, A. C. Jovens empreendedores e as dificuldades encontradas na gestão das suas empresas. Revista de Administração de Empresas Eletrônica, n. 6, p. 96-120, 2017.

MACHADO, H. P. V.; DA SILVA FAIA, V.; DA SILVA, J. D. Alerta Empreendedor: Estudo da Influência de Características do Indivíduo e do Empreendimento. Brazilian Business Review, v. 13, n. 5, p. 87, 2016.

MARIANO. R. Mudanças no campo religioso brasileiro no Censo 2010. Debates do NER (UFRGS. Impresso). v. 14. p. 119-137. 2013. 
MARTES. A. C.B.; RODRIGUEZ. C. L. Afiliação religiosa e empreendedorismo étnico: - caso dos brasileiros nos Estados Unidos. Revista de Administração Contemporânea. v. 8. n. 3. p. 117-140. 2004.

MELO. L. C. C. de. Novo Mapa das Religiões. Horizonte. Revista de Estudos de Teologia e Ciências da Religião. v. 9. n. 23. p. 637-673. 2011.

MESQUITA. W. A. B. Correndo atrás da prosperidade: trabalho e empreendedorismo entre fiéis neopentecostais. Ciencias Sociales y Religión/Ciências Sociais e Religião. v. 9. n. 9. p. 195-215. 2007.

MONT'ALVÃO NETO, Arnaldo Lopo. Tendências das desigualdades de acesso ao ensino superior no Brasil: 1982-2010. Educação \& Sociedade, [s.I.], v. 35, n. 127, p.417-441, jun. 2014. FapUNIFESP (SciELO). http://dx.doi.org/10.1590/s010173302014000200005.

NEY, M. G.; DE SOUZA, P. M.; PONCIANO, N. J. Desigualdade de acesso à educação e evasão escolar entre ricos e pobres no Brasil rural e urbano. InterSciencePlace, v. 1, n. 13, 2015.

OLIVEIRA, J. S.; PEREIRA, J. A.; DE SOUZA, M. C. D. Empreendedorismo, cultura e diversidade: a participação dos empreendedores negros nas atividades empreendedoras no Brasil no período de 1990 a 2008. Revista Contemporânea de Economia e Gestão, v. 11, n. 2, p. 7-30, 2013.

PAIXÃO. M. J. P. Destino manifesto: estudo sobre o perfil familiar, social e econômico dos empreendedores/as afrobrasileiros/as dos anos 1990. Programa das Nações Unidas para o desenvolvimento, 2003.

PINDYCK. R. S.; RUBINFELD. Daniel L. Econometria: Modelos e previsões. Ed. Campus. São Paulo. 1998.

REYNOLDS. P. D. Understanding Business Creation: Serendipity and Scope in Two Decades of Business Creation Studies. Small Business Economics. [s.l.]. v. 24. n. 4. p.359-364. 2005.

RIETVELD. C. A.; VAN BURG. E. Religious beliefs and entrepreneurship among Dutch protestants. International Journal of Entrepreneurship and Small Business.[s.I.]. v. 23. n. 3. p.279-295. 2014.

RÜPKE. J. History. Theory. and Ideology. Religion.[s.I.]. v. 46. n. 3. p.439-442. 26 maio 2016. Informa UK Limited.

SERAFIM. M. C.; MARTES. A. C. B.; RODRIGUEZ. C. L. Segurando na mão de Deus: organizações religiosas e apoio ao empreendedorismo. Revista de Administração de Empresas. [s.I.]. v. 52. n. 2. p.217-231. abr. 2012.

SINNEWE, E.; KORTT, M.; STEEN, T. Religion and earnings: evidence from Germany. International Journal of Social Economics, v. 43, n. 8, p. 841-855, 2016. 
SMITH. A. An Inquiry into the Nature and Causes of the Wealth of Nations. New York: Metalibri. 2007. 754p.

STEVENSON. H. H.; JARILLO. J. C. A. Paradigm of Entrepreneurship: Entrepreneurial Management. Entrepreneurship. [s.I.]. p.155-170. 2007.

TECCHIO. E L.; CUNHA. C. J. A. de C; SANTOS. F. B. Spirituality in organizations?. Organizações \& Sociedade (Online). v. 23. p. 590-608. 2016.

THORNTON. P. H. THE SOCIOLOGY OF ENTREPRENEURSHIP. Annual Review Of Sociology.[s.I.]. v. 25. n. 1. p.19-46. ago. 1999.

VIEIRA. J. P. V. S. Religião e empreendedorismo no Brasil: uma análise utilizando modelos de escolha ocupacional a partir do Censo de 2010. 2013. Dissertação de Mestrado. Pontifícia Universidade Católica do Rio Grande do Sul.

WEBER. M. A ética protestante e o espírito do capitalismo. São Paulo: Martin Claret. 2013. 


\section{ANEXOS}

\section{Anexo 1 - Classificação das Religiões no Brasil}

\begin{tabular}{|c|c|c|}
\hline SEM RELIGIÃO & PROTESTANTE & OUTRAS RELIGIÕES \\
\hline Sem religião & Igrejas Luteranas & Espiritualista \\
\hline Agnóstico & Outras Ev. de missão luterana & Outras espiritualistas \\
\hline \multirow[t]{2}{*}{ Ateu } & Igreja Ev. Presbiteriana & Espírita, Kardecista \\
\hline & Igreja Presbiteriana Independente & Outras Espíritas \\
\hline CATÓLICA & Igreja Presbiteriana do Brasil & Umbanda \\
\hline Católica Ap. Romana & Igreja Presbiteriana Unida & Outras umbandas \\
\hline Católica carismática; & Presbiteriana Fundamentalista & Candomblé \\
\hline Católica pentecostal & Presbiteriana Renovada & Outras candomblés \\
\hline Católica Armênia; & Outras Ev. de missão presbiteriana & religi. afro-brasileiras \\
\hline Católica Ucraniana & Igreja Ev. Metodista & Dec múlt de religiosi afro com out. religiosida \\
\hline Católica Ap.Brasil & Ev. Metodista Wesleyana & Outras declarações de religi. afro-brasileira \\
\hline Católica Ortodoxa & Ev. Metodista Ortodoxa & Judaísmo \\
\hline Ortodoxa Cristã & Outras Ev. de missão metodista & Essenismo \\
\hline Outras ortcristãs & Igreja Ev. Batista & Outras judaísmos \\
\hline \multirow[t]{45}{*}{ Outras católicas } & Convenção Batista Brasileira & Hinduísmo \\
\hline & Convenção Batista Nacional & Ioga \\
\hline & Batista Pent & Outras hinduísmo \\
\hline & Batista Bíblica & Budismo \\
\hline & Batista Renovada & Nitiren \\
\hline & Outras Ev. de missão batista & Budismo Theravada \\
\hline & Igreja Ev. Congregacional & Zen Budismo \\
\hline & Igreja Congregacional Independente & Budismo Tibetano \\
\hline & Outras Ev. de missão congregacional & Soka Gakkai \\
\hline & Igreja Ev. Adventista do Sétimo Dia & Outros budismos \\
\hline & Igreja Ev. Adventista Movimento de Reforma & Igreja Messiânica Mundial \\
\hline & Igreja Ev. Adventista da Promessa & Seicho No-Ie \\
\hline & Outras Ev. de missão adventista & Perfect Liberty \\
\hline & Igreja Ev. Episcopal Anglicana & Hare Krishna \\
\hline & Outras Ev. missão episcopal anglicana & Discipulos Oshoo \\
\hline & Igreja Ev. Menonita & Tenrykyo \\
\hline & Outras Ev. de missão menonita & Mahicari \\
\hline & Exército da Salvação & Religiões Orientais \\
\hline & Igreja Ev. Assembleia de Deus & Bahai \\
\hline & Igreja Assembleia de Deus Madureira & Shintoismo \\
\hline & Igreja Assembleia de Deus Todos os Santos & Taoismo \\
\hline & Outras Ev. de origem pent. assembleia de Deus & Outras religiões orientais \\
\hline & Igreja Congregação Cristã do Brasil & Islamismo \\
\hline & Outras Ev. de origem pent CCB & Druso \\
\hline & Igreja Ev. Pent O Brasil para Cristo & Outros Islamismos \\
\hline & Outras Ev. de origem pent o Brasil para Cristo & Esotérica \\
\hline & Igreja Ev.elho Quadrangular & Racionalismo Cristão \\
\hline & Outras Ev. de origem pent Ev.. quadrangular & Outras esotéricas \\
\hline & Igreja Universal do Reino de Deus & Tradições Indígenas \\
\hline & Outras Ev. de origem neopent universal & Santo Daime \\
\hline & Igreja Ev. Casa da Bênção & União do Vegetal \\
\hline & Outras Ev. de origem pent casa da bênção & A Barquinha \\
\hline & Igreja Ev. Casa de Oração & Neoxamânica \\
\hline & Outras Ev. de origem pent casa de oração & Outras indígenas \\
\hline & Igreja Ev. Pent Deus é Amor & religiões. cristã não determinada \\
\hline & Outras Ev. de origem pent Deus é amor & religiões. não determinada ou maldefinida \\
\hline & Igreja Ev. Pent Maranata & Dec. múlt. de religi. católica/outras religi. \\
\hline & Outras Ev. de origem neopent & Dec. múlt. de religi. evangélica/outras religi. \\
\hline & Maranata & Dec. múlt. de religi. católica/espírita \\
\hline & Ev. renovada, restaurada e reform não det & Dec. múlt. de religi. católica/umbanda \\
\hline & Pent renovada, restaurada e ref não determinada & Dec. múlt. de religi. católica/candomblé \\
\hline & Outras Ev. renovadas não determinadas & Dec. múlt. de religi. católica/kardecista \\
\hline & Igreja Ev. Comunidade Cristã & Igreja de Jesus Cristo dos Santos dos Últimos Dias/Mórmons \\
\hline & & Outras igrejas de Jesus Cristo dos santos dos últimos \\
\hline & & Legião da Boa Vontade/Religião de Deus \\
\hline
\end{tabular}

Fonte: Elaborado pelos autores a partir dos dados do IBGE e ISER (2018).

Notas:(ii) V0310. v4090 e v6121 são os nomes das variáveis que representam Religião nos microdados dos censos de 1991. 2000 e 2010, respectivamente; (ii) Ap.= Apostólica;Ev.=Evangélica; Múlt=Múltipla; Pent $=$ pentecostal; neopent=neopentecostal. 
Anexo 2 - Definição dos agrupamentos das ocupações dos trabalhadores

\begin{tabular}{|c|c|}
\hline Setor & Descrição \\
\hline Agricultura & $\begin{array}{l}\text { Agricultura. Planta de produção extrativista e animal. Extração de } \\
\text { minerais; }\end{array}$ \\
\hline Industria & $\begin{array}{l}\text { Indústrias de processamento e indústrias de construção Atividades } \\
\text { comerciais e auxiliares. Serviços de transporte e comunicações; }\end{array}$ \\
\hline Comércio & $\begin{array}{l}\text { Atividades comerciais e auxiliares. Serviços de transporte e } \\
\text { comunicações; }\end{array}$ \\
\hline Social & $\begin{array}{l}\text { Social (comunidade. médico. odontológico e ensino); } \\
\text { (Instituição de Crédito. Seguros e Capitalização. Comércio e }\end{array}$ \\
\hline Outros & $\begin{array}{l}\text { Administração de Imóveis e Valores Mobiliários. Organizações } \\
\text { Internacionais e Representações Estrangeiras. Atividades não } \\
\text { distribuídas em outras agências }\end{array}$ \\
\hline Sem_info & Quando não temos informações sobre a atividade das pessoas \\
\hline
\end{tabular}

Fonte: pelos autores a partir dos dados dos Censos de 1991, 2000 e 2010. 
Luan Vinicius Bernardelli, Lechan Colares Santos, Gustavo Henrique Leite de Castro, Ednaldo Michelon 